Dr. Smith Ely Jelliffe said that some of. Dr. Sachs' cases were. typical cases of chorea insaniens, and that moreover there was an exceedingly rich and full literature from the appearance of Krafft-Ebing's studies on chorea insaniens in 1894 to the present time. The relations of choreic disturbance to post-microbic infections, in many instances, were established.

Dr. Sachs, in reply to Dr. Brill, said that in calling these cases toxic chorea he had not been guided entirely by his own view of the etiological factors concerned in their production. The symptoms were supposed to be due to a toxin, but whether always and distinctly bacteriemic or not he could not definitely decide.

At the annual meeting of the society in January the following officers were elected for the ensuing year: President, Dr. B. Sachs; First VicePresident, Dr. J. Ramsay Hunt; Second Vice-President, Dr. Smith Ely Jelliffe; Corresponding Secretary, Dr. Max Mailhouse; Recording Secretary, Dr. E. G. Zabriskie.

\title{
PHILADELPHIA NEUROLOGICAL SOCIETY
}

\section{January 27,1908}

The President, Dr. Alfred Gordon in the Chair.

Dr. Weiss presented a patient from Dr. Spiller's service at the Philadelphia General Hospital with lateral movement of the foot in ankle clonus.

\section{FRAENKEL TREATMENT OF TABES}

By M. D. Bloomfield, M.D.

This paper brought out the points that the treatment should only be carried out by a physician who has had a good hospital training, who is thoroughly familiar with the disease and the status præsens of his case. The treatment can only be carried out successfully by one who has had a practical training from an experienced man, as the details of the treatment can only be acquired by practical assistantship. Dr. Bloomfield spoke of the loss of the sense of muscular fatigue in tabetics, a symptom not mentioned in text-books, and of the accidents (cardio-vascular hypotonias, spontaneous fractures, etc.) which could only be prevented or treated by a medical man; he also showed a man who was extremely ataxic when he first came under treatment last May, but who could now perform almost any movement.

Dr. T. A. Williams stated that the loss of sense of muscular fatigue in tabes is described by the French writers, of whom perhaps the most conspicuous one to record this fact is Dejerine. In regard to the mechanical treatment in connection with the education, Dr. Williams said that Faure of La Malon, an institution in the north of France, has worked a great deal recently at it and has written two papers on the subject, one of which was read before the French Congress of Neurologists in I906, and the other was read at the Congress at Amsterdam last year, and a third paper was read at the Congress of Geneva last August, in which he advocates the supplementing of the education movements by mechanical supports in 
the nature of elastic bands to assist in overcoming the hypotonia. He claims that this renders the education easier and adds greatly to the patient's comfort; in fact, he states that in some cases the only bar to locomotion is the hypotonia. These patients are not in reality so ataxic as they are hypotonic. In that connection, Dr. Williams mentioned another case described by the physician of another institution, on the border of Switzerland, in which he showed the remarkable results obtained by spontaneous efforts at the education on the part of the patient, that is to say, the patient on being encouraged to get out of bed makes a few faltering steps to the next bed and so educates himself. Dr. Williams, however, believes that it is a very important matter to insist upon the supervision of these exercises by a medical man. He thinks it is too commonly left to the attendants, who are not always educated in the necessary precautions to carry out the exercises and use too much vigor possibly.

\title{
ACQUIRED SPASTICITY AND ATHETOSIS
}

\author{
By William G. Spiller, M.D.
}

Haupt ${ }^{1}$ remarks that idiopathic or primary athetosis is relatively rare. Lewandowsky distinguishes between acquired athetosis and similar forms developing after hemiplegia. The former is not merely a post-hemiplegic athetosis affecting both sides, or a result of infantile spastic diplegia, but is an independent peculiar disease, whose pathology is not definitely known, but probably consists of bilateral cerebral lesions. Oppenheim also makes the distinction. Previous diplegic disturbances should be excluded if the term primary double idiopathic athetosis is employed. In a case reported by Haupt small cortical foci were found in the left parietal lobe, and seemed to indicate a previous encephalitis. A few cases with necropsy in the literature are referred to by him.

Dr. Spiller presented a patient, a boy twelve years old, in whom during the past. five years he had observed gradually developing spasticity of all the limbs with athetosis, reaching finally such an intensity that the patient was confined to his chair. The patient first came under Dr. Spiller's observation December 15, I902. At that time he was seven years old. He has been under Dr. Spiller's care at intervals since 1902. The following history was obtained in Ig02. He was the first born child. The birth was easy and normal. He was said to have had convulsions when four months old. The father stated that the boy walked, ran and jumped as other children until four months previously, but since that time had gradually been getting lame in the left lower limb, and had been obliged to wear a brace during the previous four weeks. He had not had any pain but occasionally had some tremor of the upper and lower limbs.

An examination showed that the boy was unable to stand without supporting himself by bending back the knee. When he attempted to walk the feet were wide apart, the knees were close together and the lower limbs became spastic. There was no spasticity of the limbs when the boy was at rest. The lower limbs were somewhat weak when he was walking, but very little if at all when he was sitting. The grip was good in each hand, and the voluntary power of both upper limbs was good. The patellar reflexes were prompt but there was no clonus. The plantar and Achilles reflexes were normal. When lying down the lower limbs showed no spasticity on voluntary movement. Sensations to touch and pain were normal. Each thigh could be moved passively freely. What weakness was present

\footnotetext{
${ }^{2}$ Deutsche Zeitschrift für Nervenheilkunde, Vol. 33, Nos. 5 and 6, p. 464.
} 